\title{
El repentismo onírico y el cerebro repentista
}

\section{Oneiric repentism and the poet of repentism brain}

\author{
Alexis Díaz Pimienta \\ Escritor y repentista. Director de la Cátedra de Poesía Improvisada de La Habana (Cuba) \\ alexisdiazpimienta@gmail.com
}

\author{
IMPROVISACIÓN POÉTICA Y PERFORMANCE. ASPECTOS ANTROPOLÓGICOS, LITERARIOS Y \\ MUSICALES. \\ MONOGRÁFICO COORDINADO POR MARÍA PILAR PANERO GARCÍA (Universidad de Valladolid)
}

Patrocinado por la Cátedra de Estudios sobre la Tradición (Universidad de Valladolid)

\begin{abstract}
RESUMEN
La relación entre poesía y sueño ha tenido grandes antecedentes y obras que la legitiman. Pero la relación entre poesía improvisada (repentismo) y sueños es un mundo nuevo e inexplorado. No hablo aquí de poesía onírica o mundos oníricos asociados o transportados a lo poético, sino que hago un análisis de poemas (décimas) improvisadas mientras duermo, en un viaje directo tanto al subconsciente como a la génesis de la poesía.
\end{abstract}

\section{ABSTRACT}

The relationship between poetry and dreams has had great antecedents and works that legitimize it. But the relationship between improvised poetry (repentism) and dreams is a new and unexplored world. I do not speak here of dream poetry or dream worlds associated or transported to the poetic, but rather I make an analysis of poems (décimas) improvised while I sleep, in a direct journey both to the subconscious and to the genesis of poetry.

\section{palabras ClaVe}

repentismo | poesía onírica | génesis poética | metaliteratura | tradición

KEYWORDS

repentism | oneiric poetry | poetic genesis | metaliterature | tradition

¿Y si durmieras? / ¿Y si en sueños, soñaras?
¿Y si en el sueño fueras al cielo
y allí cogieras una extraña y hermosa flor?
¿Y si, al despertar / tuvieras esa flor en la mano?

(Samuel Taylor Coleridge)

\section{Introducción}

El sino (o el azar, o la vocación, o el esfuerzo) de ser por un lado poeta improvisador, y por otro lado teórico y ensayista en torno al arte del repentismo, no es una condición fácil de resumir cuando le piden a uno que escriba sobre su oficio de siempre. No se me escapa que esa invitación entraña, posiblemente, un envite a que me defina y a que declare cuáles son las bases de mi poética. Para cumplir con el compromiso en que me veo ahora de escribir sobre las artes verbales y musicales con las que he convivido prácticamente desde que tengo uso de razón (por no decir que desde antes de nacer, pues vengo de familia de repentistas), he dado vueltas a dos opciones: la de hacer un retrato (algo que es más distanciado, más objetivo) y la de hacer un autorretrato (algo más expuesto, más delicado).

Las limitaciones del espacio me obligan a dejar estos asuntos, por el momento, aquí. Se podrá leer, son algunas confesiones muy personales relativas a la inspiración (o a la incubación) que ocasionalmente recibo a través de los sueños. Tiempo vendrá, espero, en que pueda inscribir estas experiencias que parecen únicas e intransferibles, pero que no lo son en el marco de su tradición. 

Matrix"

¿Se acuerdan de Matrix, aquella distopía cinematográfica protagonizada por Keanu Revees y Laurence Fishburne, en la que Revees (Neo) era capaz de moverse "muy lentamente", excesivamente lento, para transmitir la sensación de que lo hacía excesivamente rápido, más rápido imposible? A veces aplico esta técnica Matrix para analizar las improvisaciones: verlas en cámara muy lenta, de-cons-truir-las muy lentamente para que percibamos "Iorápido" que ocurre todo en la mente del poeta.

Eso haré ahora, para que vean cómo improvisé un pie forzado, que, además, ocurrió en sueños, uno de esos episodios de repentismo onírico que tanto llaman mi atención y que algún día estudiaré a fondo. ¿Cómo nuestro cerebro - el de los repentistas-, mientras dormimos, es capaz de armar décimas perfectas a gran velocidad, tan bien o mejor que en la vigilia?

Lo primero que debemos tener en cuenta, para no perdernos ni un detalle, es el esquema más completo de la décima improvisada —creado por mí-, y así evitamos los equívocos. De manera lineal el esquema de la décima improvisada (estándar) es este:

$$
\text { [1a-2b-3b-4a-(.)/5a-6c-7c-8d-9d-10c]8c }
$$

o sea, una estrofa de diez con sistema de rimas abbaaccddc, versos octosílabos (el 8 supraíndice) y rima consonante (la "c" supraíndice), que además lleva una pausa tras el cuarto verso para ser espinela, que es el tipo de décimas con el que improvisamos; un esquema que colocado de forma vertical se traduce en:

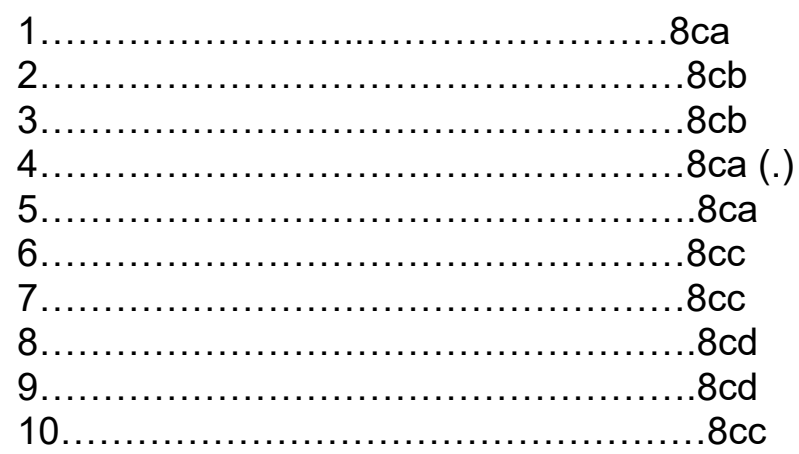

Veamos, entonces, el caso que les traigo: una décima improvisada por mí con el pie forzado "alcohólico empedernido", pero insisto, jen un sueño!, por lo tanto, este es otro caso de "repentismo onírico" (casi un subgénero), que analizaré con efecto Matrix para que veamos cómo se improvisa un pie forzado cuando hay técnica y oficio, tanta, que hasta en sueños se aplican para salir airoso.

\section{Comienzo.}

Ayer soñé con Marcelo, con mi hermano Marcelo, el otro poeta, el que murió en 2018 dejándome con todo tanto encima. Con tantos versos, que es lo que más pesa. Y en mi sueño, Marcelo no estaba solo. Lo acompañaba Horacio, nuestro vecino Horacio, el basurero del barrio que también era poeta. O el poeta del barrio que trabajaba en el camión de la basura. Qué más da. Horacio, que recitaba de memoria a Machado y a Rafael de León y a Pesa y a Buesa, que se reía en el Caballo Blanco y se sentían sus carcajadas en la Virgen del Camino. Sí, el viejo Horacio, con nombre y cara de poeta griego. Y Marcelo y Horacio estaban en mi sueño como siempre los vi en vida: sentados en el muro de la casa de Horacio, bebiendo alcohol peleón, "cayéndose a poemazos" y riéndose. Eran, no sé, las diez de la noche. Ahora que lo pienso, yo no sé qué hacía yo a las diez de la noche, allí, en el Caballo Blanco, adonde hace mil años que no voy. Cierto que allí viví toda mi adolescencia, pero aquello para mí es Comala, yo no voy: están muertos.

Sin embargo, allí estábamos los tres, ellos bebiendo y diciéndose poemas, Horacio fumando y Marcelo moviendo como aspas sus enormes manos. Yo me acerqué, risueño, y no sé por qué dije —ni siquiera sé a cuál de los dos se lo dije-: ¡coño, bróder, estás hecho un alcohólico empedernido! Y no suelo ir yo por ahí ofendiendo, o dando sermones moralistas sobre los ritos báquicos ajenos, por eso me extraña y por eso lo cuento; yo fui el primer sorprendido. Y entonces el viejo Horacio se levantó —era altísimo—, me miró fijo con sus ojos vidriosos — siempre me llamaron la atención sus ojos: como si hubiera acabado de 
llorar lágrimas negras-, y me dijo:

—Arriba, ahí lo tienes. ¡Alcohólico empedernido!

Yo miré a Marcelo y Marcelo sonrió como si sus labios se frotaran las manos.

— ¡Arriba, que tú puedes! —me dijo el viejo Horacio, y repitió en voz más alta, casi deletreándolo—: ¡Alcohólico empedernido!

Solo entonces me di cuenta. Era un pie forzado. ¡Un pie forzado! Horacio y Marcelo — creo que no lo he dicho- eran junto al viejo Jesús, mi padre —o después que él, para ser justo- mis mayores admiradores como repentista. Para Marcelo yo era Dios, así, sin metáforas. Y nada le gustaba más a Horacio y a Marcelo que juntarse en el barrio a recordar mis improvisaciones, entre trago y trago, entre carcajada y carcajada. ¡Pulvis!

Bueno, sí, algo les gustaba más: retarme. Retarme a improvisar, así, desprevenido. El culpable era yo, dijo Marcelo: por soltar un octosílabo así, a bocajarro. Y tenía razón. "Alcohólico empedernido" era un octosílabo perfecto.

Y acepté el reto, claro. Repetí el verso en voz alta y me dispuse a complacerlos.

Los conozco muy bien. Yo sé que ellos esperan, con ese verso, que haga una décima contextualizada: que hable del alcohol, de los amigos y parientes borrachos (ellos), con un poquito de humor y algo de burla. Pero yo pienso de otra forma. Voy a darle "el cambiazo" al enfoque temático, para sorprenderlos. Esta es una de las técnicas más eficaces para los pies forzados: salir por donde no te esperan, "mover el verso".

Me acerco a ellos. Pienso. Necesito algo, un elemento que pueda asociarlo al alcoholismo sin hablar de él directamente. Y lo primero que recuerdo es que los borrachos se joroban, se tuercen al andar; pensé entonces hacer la décima sobre un árbol, a un tronco jorobado "como si fuera o estuviera borracho". Bien. A la vez me di cuenta de que "alcohólico empedernido" era un verso "sin determinante", por lo tanto, tendría que encabalgar en el bajante: "el / alcohólico empedernido" o "un / alcohólico empedernido". Bien. Listo. Me decanté por "un". Encabalgando en el verso 9d terminaría diciendo "un / alcohólico empedernido". Y entonces la simple e inocente partícula "un" hizo el resto.

"Un" como rima (9d) atrajo a "zunzún" como rima (8d). ¡Zunzún! Me encanta la palabra zunzún. Y el pajarito. Entonces, cambié el árbol o el tronco jorobados que iban a actuar como borrachos en mi décima por un zunzún. Decidido: mi borracho sería un zunzún. Ahora necesitaba aspectos del zunzún que se asociaran al borracho. Metafóricamente, podía decir que el zunzún estaba jorobado, como el tronco del árbol, por qué no. Pero me di cuenta de que si el zunzún volaba, como todos los zunzunes, entonces el zunzún de mi décima podía venir dando tumbos por el aire, como los borrachos. Y entre "dando tumbos" y "un" la métrica hizo el resto. Ya tenía el verso 9d completo: "dando tumbos como un" (un símil, una de las figuras retóricas más fácil y más usadas por los repentistas). $Y$ tenía el pie forzado ("alcohólico empedernido). Y la rima del verso 8d: "zunzún". Ya tenía en mi cabeza, entonces, esto:

zunzún

dando tumbos como un

alcohólico empedernido.

Pero claro, yo soy un repentista con técnica. $Y$ sé que puedo -debo- colocar un codo sintáctico al principio del verso 7c, el que antecede al verso terminado en "zunzún". Y sé que los codos más frecuentes y socorridos - por lo tanto, los más cómodos- son "y", "porque", "pero" y "aunque". Y sé también que de estos cuatro, "y" es el más usado, y el primero que viene a la cabeza del improvisador, no me pregunten por qué. Así que pongo " $y$ " al principio del verso conector, que, no lo olvidemos, debe rimar con el pie forzado, por lo tanto, debe acabar en "-ido". Y ya tengo en la cabeza esto:

y......................ido

zunzún

dando tumbos como un

alcohólico empedernido.

Entonces, una vez más se imponen el oficio y la técnica: las palabras principales (elementos $\mathrm{X}$ ) del verso 
10c son "alcohólico" (sustantivo) y empedernido (adjetivo). $Y$ de las dos, la principal-principal es "alcohólico" (sustantivo). Y es ella la que "tira de mi cerebro" para que este le busque pareja y complete el puzle. Así es como llega a mi cabeza la palabra-rima "bebido", para llenar el hueco del final del verso conector (7c). Entonces ya tengo en la cabeza esto:

y.....................debido

zunzún

dando tumbos como un

alcohólico empedernido.

e inmediatamente, rapidísimo llené los huecos que quedaban, dejando en mi cabeza esta redondilla final (ya veremos cómo):

$Y$ de tanto haber debido

Llega a mi casa un zunzún

dando tumbos como un

alcohólico empedernido.

¿Cómo y por qué esta combinación? "Bebido" tenía algunas combinaciones posibles: dejarlo como adjetivo añadiéndole un sustantivo delante ("hombre bebido", "zunzún bebido", "pájaro bebido"); o usarlo como verbo: "he bebido", "ha bebido", "haber bebido". Me decanté por esta última, "haber bebido" (supongo que por pragmatismo métrico: tenía cinco sílabas, más la "y" del codo, seis: ya casi tenía el octosílabo. Así que ya tenía medio verso.

Y......... haber debido

No me fue difícil completarlo, la verdad (además de repentista, hice muchos crucigramas desde niño): "de tanto" encajaba perfectamente, "de tanto haber" daba un juego perfecto para quien bebe mucho (el personaje alcohólico del verso 10c). Y así quedó el verso:

Y de tanto haber debido

Y con el verso 8d pasó algo parecido. Ya tenía esto:

$\mathrm{Y}$ de tanto haber debido zunzún

dando tumbos como un

alcohólico empedernido.

Así que el complemento para el verso 8d, el del zunzún, podrían haber sido varios: "pasó a mi lado un", "vomitó mucho un", "llega a mi patio un", "llega a mi casa un", y escogí este, el de mi casa. ¿Por qué? Pragmatismo supongo: un complemento de lugar siempre da más "veracidad" al discurso, y de todos los lugares posibles, la casa es lo más íntimo y cercano, más nuestro, familiar, teniendo en cuenta que mis o interlocutores eran mi hermano y mi vecino. O sea, mi cerebro no es tonto: había que "acercarlos", implicarlos. Así que me quedó en la cabeza esta redondilla completa y "perfecta":

Y de tanto haber debido

llega a mi casa un zunzún

dando tumbos como un

alcohólico empedernido.

Entonces, ya tenía la redondilla final de mi décima, la parte más importante. Qué hacer ahora. ¿El puente, y seguir subiendo? ¡No! Soy un repentista con técnica, con oficio. Así que sabía que tocaba dar el salto al principio, al bloque I de la décima, y "amarrar" el principio con el pie forzado. Recordemos que los oyentes -el ponente Horacio, mi hermano Marcelo, y algunos vecinos- solo conocían el verso 10c, el pie forzado: "alcohólico empedernido". Y ahí estaban, expectantes. Y recordemos también que todo este proceso aquí descrito no ha consumido ni tres segundos, tal vez cinco, (para ser "humano").

$Y$ por mi técnica y mi oficio yo sé que las palabras principales del verso bloque $V(9 \mathrm{~d}$ y $10 \mathrm{c}$ ) son "alcohólico", "empedernido" y "dando tumbos" (elementos X). Necesito ahora elementos Xn, "ondas rodarinas": palabras relacionadas de cualquier manera con "alcohólico" "empedernido" y "dando tumbos". También sé que "alcohólico" es la más importante, la más fuerte, por ser sustantivo y por estar en el 
verso 10c (código público). Así que tiro de ella: "alcohólico $\diamond$ "alcohol" $\diamond$ "borracho" $\diamond$ "borrachera" $\diamond$ "bar" $\checkmark$ "botellas". Tengo donde escoger. Y selecciono las últimas dos, "bar" y "botellas". ¿Por qué estas dos? No sé: todo no puede explicarse ni saberse; dejemos algún cabo suelto para que siga pareciendo magia. Escojo "bar" y "botellas" para viajar hasta "alcohólico empedernido". Y entonces, en este momento juega un papel importante el hecho de que yo sea cubano y de la segunda promoción post-naboriana, o sea, neobarroco. Tengo "bar" y "botellas" en la punta de la lengua, pero tengo más abajo, esperando, a un zunzún que da tumbos, a un zunzún borracho. ¿Cómo alguien se emborracha? Bebiendo. ¿Y qué se bebe para emborracharse? Alcohol. ¿Y cómo es el alcohol? Líquido. Bien. Necesito líquidos para mi zunzún borracho. Y enseguida mi cerebro asocia: zunzún $\diamond$ ave $\diamond$ naturaleza $\diamond$ aire libre $\diamond$ jardín $\diamond$ lluvia. ¡Bien! La lluvia es líquida como el alcohol. Un zunzún puede embriagarse bebiendo lluvia. Me entusiasmo con este feliz "hallazgo" (= asociación de ideas). Ya tengo entonces, "bar", "botellas" y "lluvia". Necesito algo más. Necesito una figura retórica que acerque un poco palabras tan distantes como "bar" y "lluvia", "botellas" y lluvia". Un nexo. Y de todas las figuras retóricas posibles a un repentista cubano de mi generación la que más fácil se le da es la metáfora. La más cercana, la más común, la más recurrida. Y de todas las metáforas posibles la que más usamos los repentistas, por ser la más fácil —tal vez se haya hecho fácil de tanto usarla - es la llamada "metáfora de complemento proposicional". Entonces, solo necesito la preposición "de" y un complemento: "bar de" o "botellas de" para acercarme a "lluvia". ¿Dónde nace la lluvia? En las nubes, en el cielo. ¡Bien! Ya lo tengo: "bar de cielo" o mejor "bar del cielo". Metáfora perfecta, de cinco sílabas. Ya tengo entonces más de medio verso ("bar del cielo"), y las palabras "botellas" y "lluvia". Tengo que completar el octosílabo, seguir armando el puzle (ique el tiempo corre!: ¡2 segundos más!). Se me ocurre completar el primer verso con el sintagma "creo que en el...". Podrían haber sido muchos otros, pero se me ocurre este y me gusta, tiene ritmo: "creo que en el" + "bar del cielo". Y ya tengo un verso octosílabo completo y las palabras "botella" y lluvia" en la cabeza (y en la puntita de la lengua). Pero la palabra "lluvia" es pobre en rimas (infeliz), así que la desecho (oficio, técnica). Aunque no del todo. Estará "ahí dentro", metafóricamente: la lluvia es el alcohol que llena las botellas del bar del cielo. ¡Bien! Tengo entonces esto:

Creo que en el bar del cielo botellas.

Debo completar ahora ese segundo octosílabo, unir "cielo" y "botellas" (o mejor: "bar del cielo" y "botellas"). Entonces, la palabra "lluvia" juega su papel (fundamental) en este juego: si no va a servir como rima (papel fónico), ni como presencia léxica (papel métrico y sintáctico), al menos quiere ser útil como palabra significante (papel semántico). Ella es la lluvia, el alcohol metafórico que está dentro de las botellas que hay en el bar del cielo. Y sabe que, ahí debajo, lejos, pegado a la tierra, hay un zunzún alcohólico al que hay que hacer llegar su dosis de bebida. ¿Y cómo se saca la lluvia-alcohol de una botella? O se bebe, o se sirve, ¡o se rompe la botella! ¡Romper botellas!, piensa la palabra lluvia y se emociona, porque le parece poético. Y a mí también. Es poético. En mi generación casi todos los poetas repentistas rompen, rasgan, quiebran, parten, desgarran, destrozan infinidad de cosas abstractas y concretas. Es un signo estético generacional. Así que hay que romper esas botellas para que llueva alcohol y el zunzún beba. ¡Venga! (otro segundo consumido). Tengo esto:

Creo que en el bar del cielo romper botellas.

Puedo usar "romper" o un derivado: "rompo", "roto", "he roto", "han roto", "ha roto". Y me decanto por "ha roto", tercera persona. "Ha roto botellas". ¡Pero quién! No lo sé, pero me da igual: "alguien". Y ya están en mi cabeza todas las piezas: "alguien ha roto botellas". Ya tengo el bloque I de mi respuesta al pie forzado completo (1a y 2 b). Y puedo empezar mi décima:

Creo que en el bar del cielo

alguien ha roto romper botellas.

Pero no. No es tan fácil. Cuando uno se llama Alexis Díaz Pimienta y tiene oficio y técnica y es cubano y está improvisando en el siglo XXI no lo va a hacer tan fácil, así no más: qué es eso de que ya tengo los dos versos y empiezo. No. Un repentista cubano de la segunda promoción postnaboriana $-\mathrm{y}$ no uno cualquiera, sino uno que ha estudiado el repentismo desde dentro y ha descubierto "cosas" y hasta les ha puesto nombre - conoce y puede poner en práctica la llamada "técnica del enroque". Y lo hace. Es decir, lo hago. Es una técnica repentista con nombre ajedrecístico — nada casual—y consiste pensar los dos primeros versos (bloque binario entero), pero no decirlos, sino "enrocarlos", reservarlos para el final de la primera redondilla. $Y$ eso hago. $O$ sea, convierto los que iban a ser mis versos $1 a$ y $2 b$, en mis 
futuros versos $3 b$ y $4 a$.

Así que ahora tengo en la cabeza esto:

1

2

3. creo que en el bar del cielo

4. alguien ha roto botellas.

y lo único que sé, por la estructura de las redondillas, es que el verso 1a debe acabar en "-ellas" y el verso $2 b$ debe acabar en "-elo". El resto es fácil (o me parece fácil). El propio lenguaje y la técnica hacen el resto. La palabra-rima "botellas" (en contubernio con la palabra-rima "cielo") atrae a la palabra-rima "estrellas", relacionada con "botellas" por la rima (campo fónico-rimal) y con "cielo" por el significado (campo semántico).

Entonces ya tengo:

1 estrellas

2 ................................

3. creo que en el bar del cielo

4. alguien ha roto botellas.

Vamos, que se me acaba el tiempo. Tengo que terminar de "armar" la redondilla para empezar a emitir ya, porque Marcelo y Horacio se desesperan. Revisemos todas las piezas léxicas que tengo hasta ahora; en orden (del 1a al 10c): "estrellas", "bar", "cielo", "alguien", "roto", "botellas", "haber bebido", "llega", "casa", "zunzún", "dando tumbos", "alcohólico", "empedernido" (y la palabra "lluvia", que está escondida dentro de la palabra "botellas", disfrazada de "alcohol"). Y no olvidemos que los vocablos más importantes, los que más fuerza de atracción ejercen sobre otras palabras, son los sustantivos. En este caso: "botellas", "bar", "cielo", "casa", "zunzún", "alcohólico" y la escondida "lluvia". Entonces, estas son las palabras que tienen que tirar de otras palabras —ondas rodarinas, gravitación léxica- para llenar esos vacíos, para completar la redondilla inicial. Y así fue. La palabra lluvia atrajo a "llueve" (verbo, acción) y las palabras "bar", "botellas" y "alcohólico" (con la colaboración inestimable de la palabra "lluvia") atrajeron a la palabra "alcohol". Así como lo oyen: a la mismísima palabra "alcohol", la omnipresente (forma parte de "alcóholico").

Y así nace el que sería el bloque I de mi décima (1a y $2 b)$ :

Llueve bajo las estrellas

$Y$ cae alcohol en mi pelo

Un hexadecasílabo que da pie a la formación de una redondilla binaria $(2+2)$, terminada en el bloque ya pensado (rimas "estrellas"-"botellas" y "pelo"-"cielo"). Y canto entonces, con seguridad:

Llueve bajo las estrellas

Y cae alcohol en mi pelo

Creo que en el bar del cielo

Alguien ha roto botellas.

¿Por qué "pelo"?, dirá entonces el listillo de la clase, o el más curioso, sin darse cuenta de que la palabra "pelo", aquí, pese a ser la palabra-rima, es la menos importante del verso — puede hasta darse el gusto de rimar, que pasará inadvertida-. Aquí las palabras fuertes, las determinantes son el complemento "cae alcohol", que entronca semánticamente con el resto de la décima aunque Horacio y Marcelo aún no lo sepan. Este complemento entronca con "bar", "cielo", "botellas" y (fundamentalmente) con "alcohólico".

Así que esta es una primera redondilla perfecta, eficaz para responder este pie forzado. Y, resumiendo, ya tengo, entonces:

Llueve bajo las estrellas

y cae alcohol en mi pelo.

Creo que en el bar del cielo

alguien ha roto botellas. 
Y de tanto haber bebido

llega a mi casa un zunzún

dando tumbos como un

alcohólico empedernido.

O sea, tengo las dos redondillas completas, aunque Horacio y Marcelo no lo sepan: ellos, después de escuchar esa primera redondilla improvisada, solo saben que tengo, una primera redondilla y el verso pie forzado. Ante sus ojos y oídos, solo hay esto:

Llueve bajo las estrellas

y cae alcohol en mi pelo

Creo que en el bar del cielo

alguien ha roto botellas.

alcohólico empedernido.

Me falta el puente (5a-6b), pieza fundamental para que una décima sea una buena décima (sobre todo si es improvisada). Necesito un verso de desarrollo (5a) y otro de enlace (6c), con la rima "-ido", por supuesto. La rima del verso 5 a tiene que ser "-ellas", y la del 6c, "-ido", ya lo he dicho, y ya lo saben Horacio y Marcelo y los demás, que esperan ansiosos.

Para el verso de desarrollo no me rompo la cabeza: ¿Una rima con "-ellas"? Pues, "ellas" misma. Ya está. Y nace un verso muy efectivo, de tan sencillo (un verso a la vez dubitativo y sugerente):

No sé qué han hecho con ellas...

Y lo complemento con un verso 6c que recupera una palabra ("roto"), recuperación enfática, y apuesta por la palabra-rima "ruido",

Se han roto sin hacer ruido

Y no es por nada, pero también es muy atinada esta rima, por el juego ligeramente aliterativo con la palabra "roto" (el juego de las "r"), que, de paso, crea una ligera onomatopeya (nos recuerda el ruido de las botellas al romperse). En fin, que queda un puente de alto nivel (un "puente de ingeniero", digo yo):

No sé qué han hecho con ellas.

Se han roto sin hacer ruido.

Nótese que es un puente en dos pasos (1+1), nada habitual, y esto le añade fuerza. Así que Horacio y Marcelo - que aún no saben, ojo, que el borracho empedernido de mi décima es un pequeño zunzún y que lo que está cayendo del cielo es lluvia de verdad, no alcohol- empiezan a emocionarse sin sospechar que la sorpresa mayor bien ahora, en el bloque IV (7c-8d), cuando el zunzún alcohólico haga su entrada triunfal en el poema.

Solo entonces, a la altura del verso 8d, llega el golpe maestro, la jugada que convierte esta décima (gracias al timonazo del enfoque temático) en una décima de calidad superior a la media. $Y$ sorprende. $Y$ emociona. Sorpresa y emoción provocadas por la ficcionalidad improvisada, pero también por la estructura narrativa de la estrofa (un microrrelato). Y canto el resto de la décima, los dos bloques finales, y todos ya han escuchado la décima completa:

Llueve bajo las estrellas

y cae alcohol en mi pelo

Creo que en el bar del cielo

alguien ha roto botellas.

No sé qué han hecho con ellas.

Se han roto sin hacer ruido. 
Y de tanto haber bebido

llega a mi casa un zunzún

dando tumbos como un

alcohólico empedernido.

Entonces, Horacio y Marcelo se levantan y se abrazan, eufóricos, como si la décima la hubieran improvisado ellos, no yo, y a mí ni me miran. Se abrazan, sonrientes, beben un trago de ron (que me parece lluvia), dejan sobre el muro sus respectivos vasos y Horacio solo dice, hablando de mí, pero sin mirarme:

-Es el caballo.

Y Marcelo le responde, sin mirarme también, pero en voz alta para que yo lo oiga:

—Pulvis!

Y yo no puedo más. Me despierto entre feliz y molesto. Feliz por la buena décima; molesto por la hora. No ha sonado mi despertador esta mañana. Miro hacia afuera a través del cristal de la ventana. Está lloviendo.

\section{Segundo caso: Otra décima improvisada en sueños y su análisis inmediato estilo Matrix (ya en vigilia)}

Comencemos por el principio: esta es la décima improvisada mientras soñaba, hace apenas un rato.
Me encontré con una rosa
de cuerpo oloroso y blando
y le pregunté cantando
si quería ser mi esposa.
Y ella me dijo nerviosa:
Pimienta, ¿tú te imaginas
que yo acepte tus pamplinas
como otras tantas veces
$y$ al cabo de nueve meses
para un niño con espinas?

Son las 8 de la mañana. Acabo de despertar hace unos minutos, excitado aún, y lo primero que he hecho es intentar recuperar de mi memoria la décima. Sí, he vuelto a hacerlo. He vuelto a improvisar en sueños. Una no, sino varias décimas, pero solo he podido recuperar esta. Si me vieran ahora mismo: aquí sigo, aún tirado en la cama, escribiendo en el teléfono esto que están leyendo, que leerán. Voy a seguir, quiero hacerlo así, "en caliente", para que nada se desdibuje. Lo dicho: he vuelto a improvisar soñando. Los episodios de repentismo onírico cada vez me gustan más y me resultan más interesantes. En el sueño de hoy - ¿de anoche? -estaba en una controversia, pero no recuerdo con quién. Sí recuerdo, y esto es muy simpático, la emoción que sentí cuando llegué al décimo verso de mi décima. Y los aplausos. Creo que sentir esta emoción tan vívidamente en un sueño es consecuencia de mi habitual estado analítico mientras improviso. Soy muy cartesiano, y eso deja huellas. En esto lo pienso ahora, mientras escribo en el teléfono, pero a ver si me explico. Quiero decir que, en el propio sueño, dentro él aún, me emocionó haber encontrado en muy pocos segundos todos los elementos que completaban la pregunta-respuesta del final de la estrofa, sobre todo porque esos versos eran un argumento que ya no era mío (del Alexis poeta-narrador de la décima, este que está ahora escribiendo), sino del personaje poemático (la rosa) y al ser una "voz ajena" insertada en "mi voz" siempre es un reto para el repentista (o mejor, para el cerebro del repentista); un reto en el que si vence, el poeta se emociona.

Desde el punto de vista técnico esta es una típica espinela binaria y a su vez una décima anecdótica con diálogo incluido. Tiene una primera redondilla binaria (2-2), con un codo sintáctico ("y") en el v. 3b; luego un curioso puente de un solo "pretil" (ese verso $5 a$ suelto) y una segunda parte (del $6 \mathrm{c}$ al 10c) unitaria e interrogativa, que es lo que completa el diálogo y crea la sorpresa. Como añadido, las figuras literarias principales son: dilogía, interrogación retórica y prosopopeya (esa rosa que habla). 
Por otra parte, creo que el acierto poético de esta décima improvisada -ese extrañamiento que provoca sorpresa y emoción en su recepción inmediata y oral (léase, repentismo), aunque sea en un sueño- está en la clave imaginativa, fantástica, del poema: en esa rosa -flor, vegetal- devenida mujer que no solo habla y responde interrogando con ironía, sino que se sabe "embarazable" por el poeta, en una simpática insinuación de "botanicofilia" que sorprende al público del sueño, y, lo más curioso, al propio repentista soñador. He aquí la mayor -o una de las mayores- ganancia del repentismo como arte, sea real $u$ onírico: el primer sorprendido de los hallazgos poéticos una vez que ocurren es el propio poeta, el enunciante, lo que demuestra que su cerebro va por delante de él, mucho más rápido y con ligera independencia en el proceso de búsqueda, hallazgo y selección lingüísticos. Mientras la parte consciente del improvisador está pendiente de lo externo -la música, el rival, el público-, su parte inconsciente está pendiente de lo interno -el léxico, la sintaxis, la métrica, las rimas-. Y ahí se produce el milagro. Por eso cuando una décima improvisada sale bien el mismo poeta llega al verso final y se sorprende de los hallazgos que ha hecho su cerebro, no él. Y se emociona.

Volvamos a la décima.

Recuerdo que el dueto rimal "rosa"-“esposa” llegó bastante fácil -son rimas pertinentes en el contexto de una décima romántica-, y que la palabra-rima "nerviosa" fue también fácil y feliz, como consecuencia de la necesidad sintáctica y métrica: por una parte, necesitaba dar continuidad a la anécdota -me encontré a una rosa, le pregunté y me contestó-, así que el adjetivo "nerviosa" es un feliz "calzador adjetival" con función rimal (muy importante); y por otra parte, necesitaba una palabra-rima que fuera trisílaba y terminara en "-osa". Las candidatas eran muchas: "nerviosa", "piadosa", "odiosa", "porosa", "dudosa", etc. Pero mi cerebro -qué listo el tipo, ¿no?- escogió "nerviosa" -selección en el llamado eje paradigmático del lenguaje- y creo que hizo bien (yo hubiera hecho lo mismo).

Entonces, ya tenía el verso 5a íntegro ("y me contestó nerviosa”). Pero venía lo más difícil: encontrar qué me había contestado.

Tengamos en cuenta también que esta fue una décima improvisada por el modo de elaboración de "orden lógico", algo ya normal en mí -no en otros repentistas-, aunque sea en sueños, y contrario al más recomendable modo: el inverso por bloques. Esto quiere decir que en esta décima yo fui improvisando verso a verso, del $1 \mathrm{a}$ al $10 \mathrm{c}$, sin tener previamente elaborado nada, teniendo en el mismo proceso de búsqueda y enunciación los hallazgos. Entonces, al decir, "y me contestó nerviosa" yo no sabía aún qué me iba a contestar la rosa, ni mi cerebro tampoco, y eso es lo estimulante. Además, coincidía con la parte más importante de una décima: la segunda mitad: puente + segunda redondilla. Asimismo, había dejado a medias el puente, que normalmente tiene dos versos-pretiles (vv. 5a-6c), lo que me obligaba a incorporar el verso $6 \mathrm{c}$ a la respuesta del verso anterior y al final de la décima. Es más: la respuesta comenzaba en ese medio-puente y debería alargarse, pero ¿hasta dónde?

Lo más llamativo de este final de décima es que la respuesta es unitaria, o sea, abarca todo el resto de la estrofa.

Vayamos por partes.

Primero: mi cerebro, como buen dialoguista -seguramente consecuencia de tanta práctica narrativa: novela y cuentos y guiones- comienza su respuesta con un vocativo ("Pimienta"): el personaje hablante (la rosa) se dirige a su interlocutor-interrogador: el propio poeta y narrador de la historia (yo). Y lo hace con un tono dialógico cercano y desenfadado (ese tuteo: "Pimienta, ¿tú te imaginas?")

Ya en este verso se respira el tono irónico o paródico del diálogo (o de la respuesta). Al menos, es muy significativo que el personaje de la rosa responda a la pregunta con otra pregunta. Y luego de la introducción de la rima "imaginas" creo que es un gran hallazgo la incorporación de la rima "pamplinas", porque refuerza el tono irónico, casi burlesco, de la respuesta-pregunta.

"Pimienta, ¿tú te imaginas / que sigas con tus pamplinas?, canta la rosa en esta miniobra de teatro improvisado en sueños, y eso es lo que escucha el público -sí, en mi sueño había mucho público, todos conocidos, pero no recuerdo quiénes eran ni dónde estábamos: cosas del mundo onírico-; pero como el modo de elaboración de esta décima fue por orden lógico y la improvisación no deja de ser un ejercicio de habla en el que imperan dos fuerzas mayores, la estructura lineal del lenguaje y la progresión correlativa de las palabras, antes de llegar la tan significativa palabra "pamplinas" a la voz de la rosa (representada en el sueño por mi propia voz) llegaron las piezas léxicas "secundarias": es decir, "que", 
"yo", "acepte" y "tus". Entonces, cuando ya mi cerebro había encontrado estas piezas y mi voz (representando la voz de la rosa) las ha enunciado ("que yo acepte tus...") me quedaba aún encontrar la pieza clave del verso: “¿tus qué?", pieza clave que coincide, además, con la rima (también clave: 6c). Por eso cuando asoma en la voz de la rosa (mi voz) la palabra "pamplinas" todos nos emocionamos en el sueño: la propia rosa, el propio poeta (yo), el público y hasta mi cerebro. (En este momento recuerdo que hubo como una especie de gritillo contenido al estilo “isííííííí, eso es, 'pamplinas'!!”.)

Ahora mismo, analizando esta décima onírica desde la vigilia -jah, si me pudieran ver por un agujerito!: ya son más de las 9 y aquí sigo, en la cama, escribiendo en el teléfono este análisis, para no olvidar nada-; pues bien, como decía, analizando esta décima desde la vigilia, acabo de darme cuenta de que es la primera vez que uso la palabra "pamplinas" en una décima y como rima. Esto también es significativo: fijense cómo el subconsciente -que es quien opera en los sueños- echa mano del depósito lexical que tenemos todos sin discriminación, en cuanto le hace falta una pieza (oh, Borges y su "máquina de pensar"; oh, Carducci y Unamuno y "la fuerza generatriz de la rima").

\section{Seguimos.}

Ahora viene un verso que me parece -y perdón por la inmodestia de mi yo onírico- prodigioso: ese "como otras tantas veces", un verso que refuerza la ironía de la rosa, su descalificación al otro personaje, insinuando -recuerden que hay público y en toda controversia de repentismo el público juzga, premia y castiga, por lo tanto, aquí nada es casual ni inocente: pura dialéctica erística- insinuando que el tal Pimienta ya ha hecho esto mismo con otras "rosas".

Además, aunque en la secuencia enunciativa este verso pase a formar parte de un movimiento ternario (6c-7c-8d), no deja de tener también cierto aire parentético, algo típico también en la décima improvisada (fundamentalmente, en los versos $2 \mathrm{~b}$ y $8 \mathrm{~d}$ ).

Veamos este movimiento ternario -enunciación de una secuencia de tres versos octosílabos seguidos, cuando lo más natural en la décima es la secuencia de dos, movimiento binario- para que se entienda mejor:

Pimienta, ¿tú te imaginas

que yo acepte tus pamplinas

como otras tantas veces...

Esta misma secuencia versal representada con el verso parentético sería así:

Pimienta, ¿tú te imaginas

que yo acepte tus pamplinas

(como otras tantas veces)...

Y luego continuaría el resto de la estrofa.

Pues bien, el verso "como otras tantas veces" también es importante: refuerza lo irónico. Además, 1) ha habido un inteligente uso de la catáfora -ese "otras" se refiere evidentemente a "otras rosas"-; 2) ya en este verso es más notorio el simbolismo ("rosas" = "mujeres"), y 3 ) aparece el golpe más impactante para el efecto irónico y descalificador: ese "tantas veces" que sirve de rima. La suma de "a otras" y "tantas veces" convierte este verso en decisorio, definitivo, "letal" como respuesta.

Y entonces llega el bloque $V$ de la décima (vv. 9d y 10c: bajante y pie forzado), el momento climático, el final, donde una décima se salva o se hunde. Esta parte final de una décima improvisada los repentistas latinoamericanos la llamamos de varias formas: el final, el apeo, el fundamento, el cierre, el remate. $Y$ en todos estos términos se ve su importancia. Es el bloque $\mathrm{V}$ el más importante de cualquier décima improvisada. Y el poeta lo sabe. Y el público también. Y lo más importante: el cerebro del poeta también lo sabe (hasta estando dormido). De nada serviría que los ocho versos anteriores hubieran sido sublimes si estos dos versos finales no lo fueran. Los versos 9d-10c salvan o hunden. Por eso la sorpresa mayor del repentismo -para el repentista y para el público- es cuando el bloque $\mathrm{V}$ de la décima es sólido, contundente, hermoso, poético, sorprendente y cumple con su múltiple función: cierre, remate, resumen y "derribo" (esto último, si es en una controversia agonal, competitiva).

En el caso concreto de esta décima soñada hay que añadir una dificultad mayor: esos dos versos tienen 
que completar una pregunta, rematarla y dotarla de sentido para que sea tal.

Dice el poeta (o sea, dice la rosa; es decir, digo yo, dentro de mi sueño):

Pimienta, ¿tú te imaginas

que yo acepte tus pamplinas

(como otras tantas veces)

y los tres personajes poemáticos (el poeta, la rosa y yo) tenemos que encontrar, sobre la marcha, en el aquí y ahora -en el ahí y entonces que constituía el tiempo y el espacio reales del sueño- qué es lo que va a decir la rosa que se podría imaginar Pimienta. "Pimienta, tú te imaginas que yo acepte tus pamplinas...", canto en mi sueño, y en la continuidad enunciativa aparece una "y". Pero hallada y enunciada esa " $y$ " tengo que seguir hallando piezas léxicas, armando el verso 9d del importante bloque V. Entonces, mi cerebro encuentra -qué listo el tipo, de verdad, qué técnica tan depurada tiene el muy cerebro mío- la rima "meses". He aquí lo que parece magia, pero no lo es; es técnica. En unos microinstantes de un segundo mi cerebro se desentiende de la estructura lineal del lenguaje e impera o se impone la estructura rimal de la estrofa. Esto es muy importante. Mi cerebro halla la rima "meses" para "veces" (8d). (Hoy no toca la lección de seseo-ceceo y su pertinencia o no caribeña) Es más, mi cerebro halla una frase hecha que constituye metonimia y símbolo: "nueve meses", para rimar con "veces". Entonces ya mi cerebro tiene -antes de enunciar esa parte de la décima- las piezas siguientes:

Pimienta, ¿tú te imaginas

que yo acepte tus pamplinas

(como otras tantas veces)

y......................nueve meses

e inmediatamente busca y encuentra el complemento perfecto, idóneo, pertinente: "al cabo de", locución adverbial de tiempo que viene como anillo al verso para completarlo sintáctica, semántica y métricamente.

Pimienta, ¿tú te imaginas

que yo acepte tus pamplinas

(como otras tantas veces)

y al cabo de nueve meses...

Pero falta lo peor. O lo mejor. El verso 10c, el pie forzado, el pollo del arroz con pollo en una décima. Así que mi cerebro... Bueno, siempre lo he dicho. Llega un momento, cuando hay mucha experiencia y oficio, que el cerebro del poeta es mucho más poeta que el poeta. Y este es uno de esos casos. Cuando el poeta-enunciador -yo, en mi sueño- estaba pendiente de encontrar un buen verso 10c, ya mi cerebro estaba por delante y había encontrado no sólo una rima, sino la rima más pertinente entre todas las rimas pertinentes: la palabra-rima "espinas". Una palabra-rima que cerraba perfectamente el círculo semántico y argumental: "rosa" $\rightarrow$ "espinas".

Pimienta, ¿tú te imaginas

que yo acepte tus pamplinas

(como otras tantas veces)

y al cabo de nueve meses

.espinas.

Aún hay más.

Mi cerebro -que en esto del repentismo es, como dicen en España, "un cerebrito"- ya había encontrado también el complemento perfecto para espinas: "niño". Mi cerebrito había hecho los deberes asociativos antes que yo. Así: poeta (hombre) busca rosa (mujer) y quiere casarse (sexo) y la rosa-mujer imagina que tras el embarazo (nueve meses) puede tener... ¿Qué? Por supuesto, un niño (o una niña, en todo caso, una personita fruto del amor entre ambos: una rosa y un hombre).

Entonces mi cerebrito ya tiene todo esto antes que el público y antes que el propio poeta, porque no olvidemos que en la oralitura un poeta no será dueño de los versos hasta que los enuncie.

Pimienta, ¿tú te imaginas 
que yo acepte tus pamplinas

(como otras tantas veces)

$Y$ al cabo de nueve meses

niño con espinas.

Aquí no pasemos por alto la importancia del "con". Otro nexo entre "niño" y "espinas" no hubiera creado el mismo efecto.

Y el último gran hallazgo de mi cerebro -no mío, insisto, yo estaba durmiendo- fue el verbo "parir". Otra vez un buen trabajo en los ámbitos del campo semántico, la idoneidad léxica y la pertinencia lingüística. Tengan en cuenta que en el margen silábico que se ha dejado el cerebro a sí mismo -y a mi voz ejecutora- apenas cabe una palabra de dos sílabas, porque el sintagma "niño con espinas" tiene ya seis sílabas y necesita ocho. Solo ocho. He aquí otra vez la importancia del concepto "espacio silábico" en la improvisación de décimas. ¿Entonces? No nos podemos olvidar del verso 9d, ese "primer hemistiquio" del hexadecasílabo que constituye el bloque $\mathrm{V}$ de la décima y que impone el rumbo sintáctico (o más bien, lo continúa: el rumbo lógico-sintáctico ya venía impuesto por el subjuntivo "acepte" del verso 7c).

Canto:

Y al cabo de nueve meses ...[niño con espinas].

Poco margen me queda (nos queda) para completar el verso (la décima). Dos sílabas.

Ahora, ya despierto, y con el Alexis analítico más conectado que el Pimienta repentista, me doy cuenta de que lo que encaja perfectamente en ese hueco, si quiero respetar la prosodia binaria de la décima improvisada, es un verbo. Un verbo de dos sílabas. Y, ya despierto, hago la misma operación de zapa lexical y encuentro tres posibles verbos bisílabos en subjuntivo: "nazca", "tenga", "para". O sea, que había tres posibles versos 10:

- "nazca un niño con espinas"

- "tenga un niño con espinas"

- "para un niño con espinas"

Pero mi cerebro, que es más listo que yo, escogió el vocablo "para" (de "parir"). Y me gusta. Me emociona. Me convence tanto ahora, en vigilia, como en el sueño. Me convence del mismo modo en que convenció al público del sueño, que terminó aplaudiéndome. Pero, ¿por qué "para" y no "nazca" o "tenga"). Porque el verbo "parir" es más fuerte, directo, inequívoco, más gráfico para lo que quiere transmitir el poeta, creo yo (despierto). Por lo tanto, su impacto es mayor, tanto en el propio emisor (mi yo soñante), como en el rival de la controversia soñada (no recuerdo quién era, pero era "el otro"), como en el público, el numeroso público de los aplausos.

Y los aplausos fueron tan fuertes que me despertaron. $Y$ la emoción provocada por esta nueva décima improvisada en sueñas fue tan fuerte que aquí sigo, en la cama, escribiendo este análisis.

Por último, el proceso de lo que yo llamo en mi último libro "gravitación léxica improvisatoria" en esta décima fue el siguiente: La palabra "rosa" atrajo a "cuerpo oloroso" (atracción semántica), y a "esposa" y a "nerviosa" (atracción fónico-rimal), pero también a "ella" (atracción catafórica), a "otras" (también catafórica) y a "espinas" (atracción semántica); la palabra "blando" atrajo a "cantando" (atracción fónicorimal); la palabra "imaginas" atrajo a "pamplinas" (atracción fónico-rimal); la palabra "pamplinas" atrajo a "espinas" (atracción fónico-rimal, reforzada por la atracción semántica previa de la palabra "rosa"); la palabra "acepte" atrajo a "para" (atracción semántico-concordante); la palabra "veces" atrajo a "meses" (atracción fónico-rimal); la palabra "meses" atrajo a "nueve" (atracción semántica); la frase "nueve meses" atrajo a la locución adverbial "al cabo de" (atracción semántica) y a la palabra "niño" (también semántica). Como ven, todo un entramado cuasi laberíntico. Por eso a veces digo que una décima improvisada es un puzle lingüístico en el que a algunos jugadores les faltan piezas y a otros les sobran.

Y ya está.

Necesito un café. Necesito volver a la vida real. Ya estoy despierto. Voy a releo, a corregir erratas (escribir en el móvil es un deporte de alto riesgo) y lo compartiré con mis lectores. A ver qué les parece. 


\section{Tercer caso: "Regreso a la infancia". Otra décima improvisada en sueños}

He aquí un nuevo sueño, una nueva décima soñada y un nuevo análisis. En este suelo es de día y estoy en el Diezmero, el barrio de mi infancia, pero no sé cómo he llegado hasta ahí. La famosa Garita del Diezmero ha desaparecido, pero hay en su lugar una avenida muy ancha. Llega una guagua y es una Leyland gris plateada, con una especia de cenefa metálica dorada a todo lo largo. Me emociono y lo comento con mis hermanos mayores, Adriana y Raimundo. ¡Qué bueno que hayan recuperado las Leyland!, digo. Son las guaguas de mi infancia, pienso o digo en voz alta, no recuerdo bien. Me fijo en el número: 213. Qué curioso, pienso, esta ruta es la ruta que antes iba del Diezmero al Reparto La Cumbre, la guagua que tomaba cada mes para llevar a mi abuela a cobrar su chequera en Dolores. Pero hay algo falso, o falso no, inexacto en todo esto. La ruta 213 iba de 10 de octubre, pasando por Dolores, hasta La Cumbre, ida y vuelta, pero no llegaba ni pasaba por El Diezmero. No importa. Subo. Reconozco el ruido del motor, el temblor de las Leyland. Me emociono otra vez. La 213 está vacía como siempre. Yo llevo una maletica de viajes (tipo trolley) y no sé dónde ponerla. Finalmente, me siento. Pero a los pocos minutos Adriana me hace señas desde la calle para que baje. No sé cómo lo ha hecho, pero Adriana ya está en la calle, a muchos metros delante de la guagua. Es una calle que no tiene asfalto y hay mucho polvo. Yo me bajo a regañadientes, porque no reconozco el lugar, y me bajo sin maleta. Adriana me dice que no me preocupe, que tío Juan Antonio nos está esperando. Mi hermano Raimundo ya no está con nosotros y Adriana me haces señas desde lejos para que la siga. Curiosamente, ya la guagua Leyland no es una guagua Leyland, sino una carriola plateada y dorada. Yo le pregunto a Adriana: ¿y qué hago con la guagua? Y Adriana me responde: No te preocupes, tío Juan Antonio se la lleva. Tío Juan Antonio lleva más de veinte años muerto, pero en mi sueño está sin camisa (como siempre), con un vientre negro y durísimo y grandísimo, negro, pero más claro que el resto de su cuerpo: tío Juan Antonio era negro de cuerpo y mulato de vientre. Entonces, Adriana y yo hablamos en una esquina, miro a mi alrededor y me doy cuenta de que hemos llegado no al Diezmero ni a La Cumbre, sino a mi antigua casa de la antigua Isla de Pinos. Estoy en Nueva Gerona, frente a una casa pequeña de madera del Reparto Micons. Esta es la primera casa de mi infancia, la primera casa de la que tengo memoria. Me emociono otra vez. Sentados en el portal, como si estuvieran esperándome, hay dos músicos con sus instrumentos. Un tres y una guitarra. Son negros, los instrumentos no, los músicos. Uno de ellos, el del sombrero, se parece mucho a Pedro Sánchez, un viejo tresero negro que me acompañaba cuando yo era joven en La Habana. Lo destaco, porque no abundan los treseros negros. Ni los laudistas. Solo los recuerdo a Reynoso y él, en los años 80 y 90. Detrás de ellos, tímidas, mis primas del Reparto La Cumbre me sonríen. Y junto a ellas, mi madre, que sonríe también. "A ver si es verdad que tú improvisas... canta", me dice el negro tresero parecido a Pedro Sánchez, sonriente. Oigo entonces el punto guajiro afinado "al aire", un toque antiguo que me emociona aún más. Lloro, y no me sale la voz. Quiero cantar, pero no me sale la voz. Los músicos me dan dos, tres entradas... y al fin canto.

\section{En este trozo de suelo}

y esta casa de madera...

Hago la pausa típica de la tonada libre o vueltabajera, miro a mi hermana Adriana que está tan emocionada como yo, escuchándome. "Pero no llores, tonto", me dice. Cierra la música y repito los dos primeros versos:

En este trozo de suelo

y esta casa de madera

y luego añado, para completar y cerrar la primera redondilla:

jugaba yo cuando era

solamente un pequeñuelo.

Las lágrimas no me impiden ver la emoción de los músicos. Y a mis primas y mi madre que aplauden. Cierra la música otra vez, e improviso un puente del tipo llamado "en dos pasos" (bueno, llamado así por mí: cuando en lugar de un verso hexadecasílabico (16 sílabas continuas) el poeta crea dos versos octósilabos simples, y los suma):

Ya se me ha caído el pelo.

Ya tengo los sueños rotos. 
Vuelva la música, vuelve el cierre musical, y remato con una perfecta redondilla de cierre, encabezada por un inequívoco codo sintáctico ("pero"), que cumple la función del tren de aterrizaje: avisa a todos de que ya viene el remate. Digo entonces, contemplando a varios vecinos que se han ido acercando y a mi hermana y a mi madre y a mis primas y a los músicos, a todos:

Pero hay tantos alborotos

y vecinos dando vueltas

que tengo lágrimas sueltas

emborronando mis fotos.

Sin duda, una excelente décima improvisada. Otra excelente décima improvisada en sueños. Y lo digo no porque haya sido yo, porque en el fondo no he sido yo, yo estaba dormido, ha sido mi cerebro. Mi cerebro ha logrado improvisar, despierto él mientras yo estaba dormido, una décima con mucha técnica, con movimientos binarios perfectos (es estructura hexadecasilábica, excepto el puente), con el grado de interiorización como recurso literario, décima vivencial, autobiográfica. Qué listo mi cerebro. Ha hecho una décima que arranca lágrimas al personaje poemático que soy yo en mi propio sueño, pero también lágrimas y aplausos a toda la familia, a todos mis vecinos. Mi tío Juan Antonio se acerca y me abraza. Los músicos sonríen. Y entonces yo, despierto.

Es lunes 5 de abril de 2021. Y al despertarme, solo, en Sevilla, como es ya acostumbre en mí, tomo el teléfono móvil para ponerme a escribir los primeros versos que vienen a mi mente. Es un buen ejercicio, entre la escritura automática y la improvisación escrita. A veces salen décimas, a veces sonetos, a veces verso libre, a veces una oración o un párrafo para novela o cuentos, a veces versos sueltos, ideas, nada serio. Comienzo a escribir y en ese momento no me acuerdo del sueño, no recuerdo aún que he soñado que improvisaba ni la décima. Comienzo a escribir poemas breves (micropoemas), pensando en mi libro zona Wi-Fi, que tiene una primera parte intitulada "Poemas muy breves de títulos muy largos". Y nacen estos (aún sin títulos):

Primer poema:

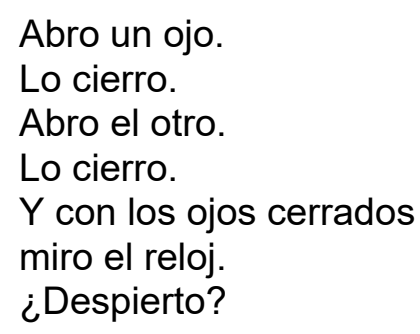

Segundo poema:

Hay millones de móviles.

Hay millones de personas

con teléfonos móviles.

Hay millones de seres inmóviles

que llevan una fábrica de soledad

en el bolsillo.

Tercer poema:

Me encantan las camas

con muchas almohadas.

Tan blancas, tan blandas.

Tan grandes.

Me dan la misma sensación

de una bañera llena de espuma.

Me duermo sumergido en falsa agua.

Vuelvo a ser pez. Feliz.

Estas son, en realidad, ideas recuperadas de la noche anterior, cuando el sueño me venció y me impidió escribirlas, desarrollarlas. Pero ideas que estaban ya en mi "disco duro". Me encanta este juego de contención que es la micropoesía. Y me encanta el trasiego creativo que me traigo entre vigilia y sueño, 
entre "despiertavela" y duermevela. Pues bien, solo tras escribir el tercer micropoema recordé el sueño recién soñado y me dije a mí mismo: "tengo que contarlo", o sea, que tenía que intentar recuperar la décima.

Para poder recuperarla, entonces, cierro los ojos y evoco la emoción. Las lágrimas. Y lo primero que hago es poner en práctica uno de los ejercicios de mi método para la enseñanza de la improvisación: "tirar de la rima-baliza". Tomo como baliza de los versos las rimas consonantes y tirando de las rimas podré ir armando la décima, apoyado en la estructura fija (abbaaccddc) y el poder atractor de las palabras.

Conocedor de la estructura, yo sé que cada rima me irá llevando a sus parejas. Pero ni siquiera me hizo falta esto. Me llegaron de golpe los dos primeros versos: En este trozo de suelo / y esta casa de madera. Y ahora sí, la rima "suelo" me llevó a la rima "pequeñuelo" y la palabra "pequeñuelo" (tetrasílaba) me ayudó a completar en mi memoria el posible cuarto verso "cuando yo era pequeñuelo". Pero no. Enseguida me di cuenta de que este no era, no exactamente, porque la palabra "era" la necesitaba como rima para el tercer verso, para rimas con "madera". ¿Entonces? Entonces descubrí el encabalgamiento: si el verbo "era" lo usaba como rima 3b, quiere decir que había encabalgado los versos $3 \mathrm{~b} / 4 \mathrm{a}$, hasta terminar en "pequeñuelo". Y gracias a esto descubrí —o me llegó a la memoria - el complemento del siguiente verso: "solamente un", de manera que ya tenía al menos la rima 3c y el verso 4a íntegro:

.......................era

solamente un pequeñuelo.

La sintaxis hizo el resto. Ya tenía los versos 1a, 2b y 4a, íntegros, más la rima 3b ("era"), que empalmaba con el verso $2 b$ terminado en "madera". Entonces, no me fue difícil hallar las otras piezas léxicas para completar un verso "sintácticamente pertinente": "jugaba yo cuando era". Y así recuperé la primera redondilla completa.

En este trozo de suelo

y esta casa de madera

jugaba yo cuando era

solamente un pequeñuelo.

Luego, la rima "pequeñuelo" me llevo directamente a la rima "pelo" y la rima "pelo" tiró de mi memoria para reconstruir un octosílabo perfecto y musical: Ya se me ha caído el pelo.

Y aquí dudé de cómo seguía la décima. Solo recordaba que el importante verso 10c (el pie forzado) terminaba con la rima "otos". O sea, que mi verso final, el décimo, rimaba en "otos". Pensé: ¿Fotos, rotos, remotos, alborotos? Recordé, entonces (todo esto en segundos), que "alborotos" era la rima del séptimo verso, no del final, ni del puente. Y por oficio y técnica, sabía que de todas las rimas posibles la rima más feliz, la mejor para el remate estaba entre "rotos" y "fotos", casi mejor esta segunda (un sustantivo siempre tiene más peso léxico-semántico que un adjetivo). Pero, si había usado "rotos" como rima, ¿rotos qué?, me dije. Y apareció como por arte de magia el sintagma adjetival "sueños rotos", un sintagma manido, sí, bastante manoseado, pero que renacía y se usaba bien en cada poema. Y algo me dijo en mi interior —oficio, técnica, experiencia- que "sueños rotos" lo había usado en el puente, no en el final, como rima 6c. Y así me llegó (recordé) el sexto verso completo, apoyado en el recurso anafórico, que me lo puso fácil: Ya tengo los sueños rotos.

Y más fácil aún me fue encontrar (recordar, recuperar) el verso $7 c$, porque ya sabía que tenía en él la palabra-rima "alborotos" (tetrasílaba), y que, verso 7 al fin y al cabo —más técnica, más oficio—era muy probable que lo hubiera empezado por un codo sintáctico (pero). Así que ya tenía más del $70 \%$ del verso completo:

Pero........... alborotos...

Y no me fue nada difícil completarlo:

Pero hay tantos alborotos...

Por supuesto, las rimas "rotos" y "alborotos" ya me habían delatado que la rima final, la más pertinente para el verso de cierre, era la rima "fotos". Por eso el resto fue fácil. Inmediatamente, supongo que por el 
contexto lingüístico y situacional, recordé mi llanto y el sintagma "lágrima sueltas". Y "lágrimas sueltas" me hizo recordar el uso del sintagma "dando vueltas" como rima. Así que ya tenía memorizado casi todo el final, casi toda la segunda redondilla, a saber:

Pero hay tantos alborotos dando vueltas

lágrimas sueltas mis fotos.

Y el oficio hizo el resto, completándome los versos con los sintagmas más pertinentes para que hubiera una segunda redondilla equilibrada, contundente, emotiva. a Saber: "y vecinos" (8d), "que tengo" (9d) y "emborronando" (10c), de forma que quedó la redondilla de este modo:

Pero hay tantos alborotos

$y$ vecinos dando vueltas

que tengo lágrimas sueltas emborronando mis fotos.

Y ya no recuerdo cómo siguió el sueño. No recuerdo si los vecinos aplaudieron más o lloraron rieron, si mis primas me abrazaron, si mi madre fue feliz, si mi hermana sonrió, como siempre, si apareció otra vez mi hermano Raimundo, que había desaparecido en el sueño, si regresó tío Juan Antonio después de haber aparcado mi carriola Leyland, o si volvió con ella, para que sus sobrinos regresáramos a La Habana, a la realidad, al presente del sueño. Solo sé que otra vez mi cerebro lo hizo: improvisar en sueños. Y otra vez yo lo he hecho: analizar en la vigilia la décima soñada.

Ya pasado el subidón emocional del ejercicio, creo que contribuyó a que este sueño fuera posible el hecho de que ayer, domingo 4 de abril de 2021, impartí las dos primeras clases online de mi "Decimódromo permanente", en Academia Oralitura, y que durante casi cuatro horas estuve enseñando a improvisar a un grupo pequeño de quince alumnos. $Y$ en esas primeras clases, en las que les hice un test de improvisación y otro de décima escrita, una de las verdades que más repetí fue que ellos tenían que lograr una separación entre el improvisador y el cerebro. Intenté convencerlos (y demostrarles) de que ellos no improvisan, pero su cerebro sí. Que la única manera de improvisar bien era dotar al cerebro de todas las herramientas, reglas, estrategias y técnicas de la improvisación, y luego confiar en él, dejarlo improvisada solo. Que solo cuando el cerebro es el que lleva "las llaves del coche", les dije, y conduce él por las autovías del idioma, el improvisador llega a un estado de éxtasis creativo que lo libera y congratula. Y es entonces cuando logra eso que algunos llaman "entrar en trance". Entonces, creo que el haberme acostado con tal nivel de excitación académica, lo que provoca en mí la enseñanza de la improvisación, contribuyó a que una vez conseguido el sueño profundo pasase lo que pasó: que llegara yo a mi infancia, a mis tres barrios (El Diezmero, La Cumbre, Micons), a mi familia, y al niño repentista que fui hace tantos años, y que volviese a improvisar frente al porche de madera de mi casa pinera (pinera y pionera y primera, todo con rimas, algo muy sintomático y simpático: rimado también). Al menos eso creo.

Por último: hace pocos días murió en Cuba, con 101 años, el viejo Melecio, una leyenda del punto guajiro en la antigua Isla de Pinos, la actual Isla de la Juventud. Y un periodista cubano me pidió por Facebook que le escribiera unas décimas de despedida, sabiendo, porque lo he contado varias veces en prensa, mi relación de niño con Melecio y con su Peña. La Peña de Melesio, famosa desde hace más de 50 años en la Isla de la Juventud, era un espacio cultural doméstico en el que yo improvisaba siendo niño y en el que Melecio era su mecenas, su Domingo del Monte, mi anfitrión. Escribí entonces unas décimas elegíacas y emotivas para despedirlo. 